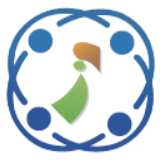

\title{
Transient Operation of a Four-Leg Inverter in Rooftop Solar Connected to a Grid Using Optimized Constructive Neural Network
}

\author{
Dedy Kurnia Setiawan ${ }^{1,2}$ \\ Mochamad Ashari ${ }^{1 *}$ \\ Heri Suryoatmojo ${ }^{1}$ \\ ${ }^{1}$ Department of Electrical Engineering, Institut Teknologi Sepuluh Nopember, \\ Surabaya 60111, Indonesia \\ ${ }^{2}$ Department of Electrical Engineering, Universitas Jember, \\ Jember 68121, Indonesia \\ * Corresponding author's Email: ashari@ee.its.ac.id
}

\begin{abstract}
This research attempted to control a Four-Leg Inverter (FLI) on microgrid rooftop solar (MGRS), which connects to a distribution network (grid) via a distribution transformer. The connected load on an MGRS system comprises two loads: nonlinear load and unbalanced linear load. Rooftop Solar (RS) injection current on each grid phase fluctuated depending on irradiation value. Load and irradiation fluctuations and RS capacity differences on every phase caused the transformer's current unbalance and harmonic. Since the pulled current load varied between grid phases, the current load's instantaneous fundamental power demand (active and reactive) also differs for each phase. Optimized Constructive Neural Network (OCNN) with single-phase PQ theory was utilized to independently control FLI in every phase determined by fundamental power demand. Therefore, a transformer would perceive load and RS injection as balanced despite varied and unbalanced conditions. OCNN builds networks by self-constructive methods. Each training session enables the addition of new hidden layers and neurons inside each layer. The OCNN network compares the error value associated with the training results to the error value associated with the temporary best network (TBN). Throughout each training session, this comparison is made to determine the network with the lowest error value or the global best network (GBN). The frequent irradiation fluctuation indicated that the system often stayed in a transient rather than a steady-state. In high transient conditions, the performance of the proposed controlling method had been tested in simulations. The result revealed that the OCNN controller obtains the lowest peak values under high transient conditions, namely $2.62 \%$ for PCU and $6.73 \%, 7.33 \%$, and $6.63 \%$ for THDi, respectively, at phases A, B, and C.
\end{abstract}

Keywords: Current unbalanced, Optimized constructive neural network (OCNN), Rooftop solar, Microgrid, Singlephase PQ theory, Four-leg inverter, Boost rectifier.

\section{Introduction}

In several countries, the usage of rooftop solar or RS has been significantly increased. Nowadays, rooftop solar is installed not only in industrial settings but also in typical household backgrounds. For example, in India, a solar power plant is targeted to produce $100 \mathrm{GW}$ in 2022, which the $40 \mathrm{GW}$ it generated by rooftop solar. In Japan, in November 2009, the feed-in-tariff (FIT) scheme for rooftop solar was introduced. This Japan FIT scheme supported rooftop solar generator development to approximately $1 \mathrm{GW}$ in 2010 [1]. The increasing number of RS consumers indirectly creates a microgrid (MG) at an electrical distribution system. This practice has been proven to change consumers' load patterns from conventional (passive) to active. The approach also allows consumers to act as electricity producers, especially if the RS system has produced an electrical surplus[2-4].

Fig. 1 demonstrated the basic structure of Micro Grid (MG) with Rooftop Solar (RS) as a power source (MGRS) using radial topology. All RSs are connected by a single-phase inverter and linked to a distribution network. Connecting MGRS with a grid 


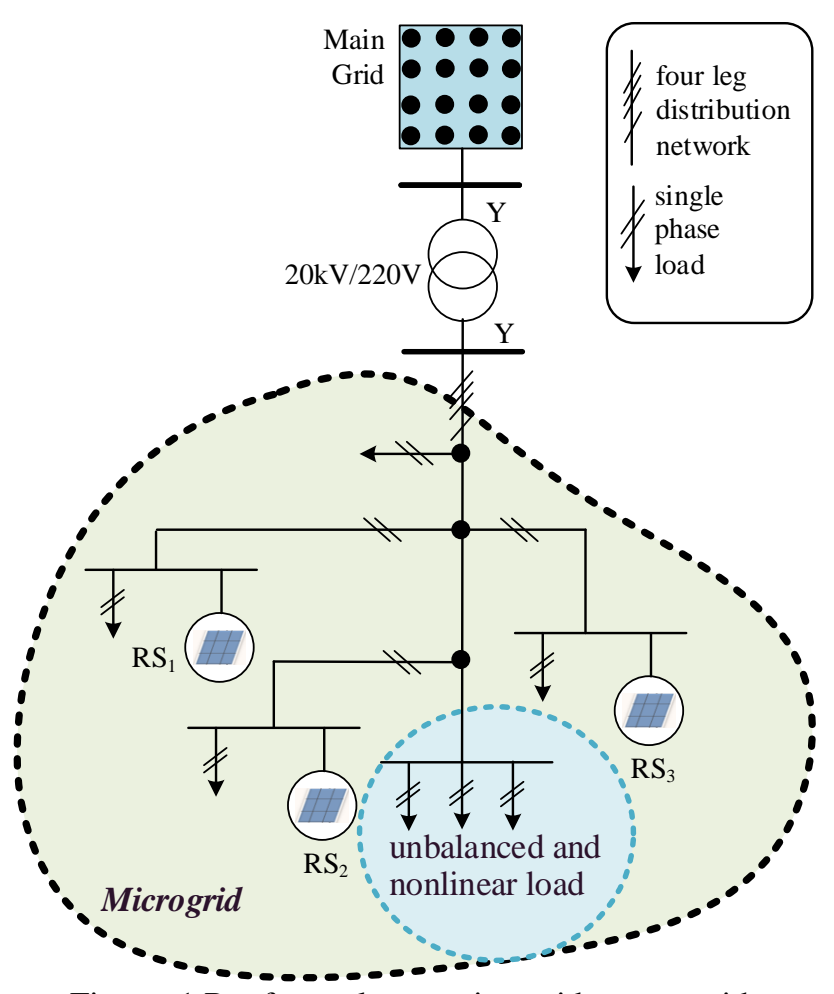

Figure. 1 Rooftop solar on microgrid system with unbalanced loads

revealed advantages, such as decreased transmission/distribution losses and higher MGRS efficiency [5]. However, the presence of RS inside MG has a drawback since it increases the uncertainty of the electric current due to natural conditions. Additionally, the significant prevalence of renewable energy contributes to challenges of stability and power quality. This issue arises due to RS's stochastic and intermittent attributes [6,7], which created several issues that must be addressed carefully to maintain acceptable power quality.

The most frequent issue on MGRS is current unbalance and harmonic [8-12]. An unbalanced MGRS was caused by irradiation difference, RS capacity, and a fluctuated load. In addition, unbalance current would impact the rising number of copper losses in a network. Copper losses are proportionate to the square root of current, and these losses will surge as current unbalance rises [13-15]. Current unbalance also produces excessive heat at the electrical motor and transformer, which leads to melted winding insulation. Furthermore, if an electric motor's torsion becomes unequal, it will reduce its efficiency and increase its vibration, raising the motor and equipment's chances of being broken. However, there is not any standard limit for the current unbalance [16].

The RS power plant utilized an electronic power converter, which requires multiple stages of DC/AC or DC/DC/AC conversion. The use of a converter degrades the quality of power delivered to a distribution network. When operated, the current value was below or above nominal; however, the resulting non-sinusoidal current caused harmonic distortion at the source and load. As a result, the issue becomes more critical when the nonlinear load is added to the network.

Numerous research has identified a range of control methods for voltage and current balance. For instance, Vechiu et al. [17-19] proposed a Four-Leg Inverter (FLI) with a modified synchronous reference frame management technique. This approach is based on decomposing three-phase voltage and current in a synchronous reference frame into symmetrical components (positive, negative, and zero).

Previous research has conducted thoroughly comprehensive studies about several ways to address the weaknesses of the linear control method on harmonic and unbalance compensation, such as utilizing nonlinear control of dead beat (DB), model predictive control (MPC), and shift mode control (SMC). Moreover, another method that has been used to increase the control system's performance so the system will be more stable and dynamic was a mixed controller such as the combination of DB repetitive control and feedforward compensation technique [20]. However, the hybrid combination is a convoluted method, which makes it hard to be implemented. A method based on $\mathrm{H} \infty$ optimization is more comfortable implementing [21], but this method only compensates for unbalanced voltage's negative sequence component.

Nevertheless, earlier studies still left some issues, such as a DC power source still required to store energy to conduct compensation. Therefore, this energy storage will be utilized as a DC source of compensator while injecting power to a distribution network via a two-way converter. However, this control technique's main disadvantage is that it required an enormous DC storage media and a limited storage element, which led to limited compensation duration. As a result, several researchers have replaced power sources with RS [22]. However, RS usage is not the best solution as the compensator cannot work correctly due to RS's stochastic and intermittent properties.

This research will focus on the control scheme for each FLI phase which operated unbalanced and varied. The main goal is to effectively balance the current grid while supplying loads with a lower harmonic load. This study aims to give several contributions to addressing the preceding research weakness. First, an implemented method is a singlephase PQ that compensates each stage independently. Power calculations are conducted instantaneously to 
provide real-time active compensation, especially during transient conditions. The fundamental instantaneous active power demanded by each load phase is previously calculated. Therefore, the active power will re-distribute equally to the distribution transformer and IEL. Second, DC source utilization of a three-phase output boost rectifier originates from the same distribution network; thus, it will provide unlimited compensation duration. Additionally, the solution proposed utilizes an Artificial Neural Network (ANN).

ANN, especially Levenberg Marquardt Neural Network (LMNN), is employed because they are great at estimating nonlinearity, do not require an accurate mathematical model system, and provide reference tracking control, particularly during transients [23-27]. In several investigations, an LMNN controller was utilized to operate the FLI. Generally, this approach is constructed by determining the number of hidden layers and neurons included within each layer $[15,28,29]$. The disadvantage is that training must be repeated numerous times to obtain minor differences between the target and the training results. As a result, the process is lengthy. This issue will deteriorate more if there are a large number of LMNN input signals.

The LMNN controller utilized in this article is an Optimized Constructive Neural Network (OCNN). OCNN is a modification of the LMNN technique. OCNN constructs Levenberg Marquardt networks by self-constructive approaches. Each training session allows for an increase in the number of hidden layers and neurons inside each layer. The OCNN network compares the training results' error value to the error value on the temporary best network (TBN). This comparison is conducted throughout each training session to obtain the network with the lowest error value or the global best network (GBN). Additionally, the amount of OCNN inputs will be minimized by employing the Pearson correlation approach to correlate each input variable with the output [30]. The proposed controller's response is compared to that of standard LMNN control approaches for transient operation.

This research is divided into five sections. The first section serves as an introduction, while the second addresses MGRS modeling. This section examines microgrid circumstances in which the RSs fluctuate, and the load is unbalanced and nonlinear. The third section describes the control strategy for single-phase PQ theory that is based on OCNN. The fourth section will explain the simulation results and discussion. The final section will address the research conclusion.

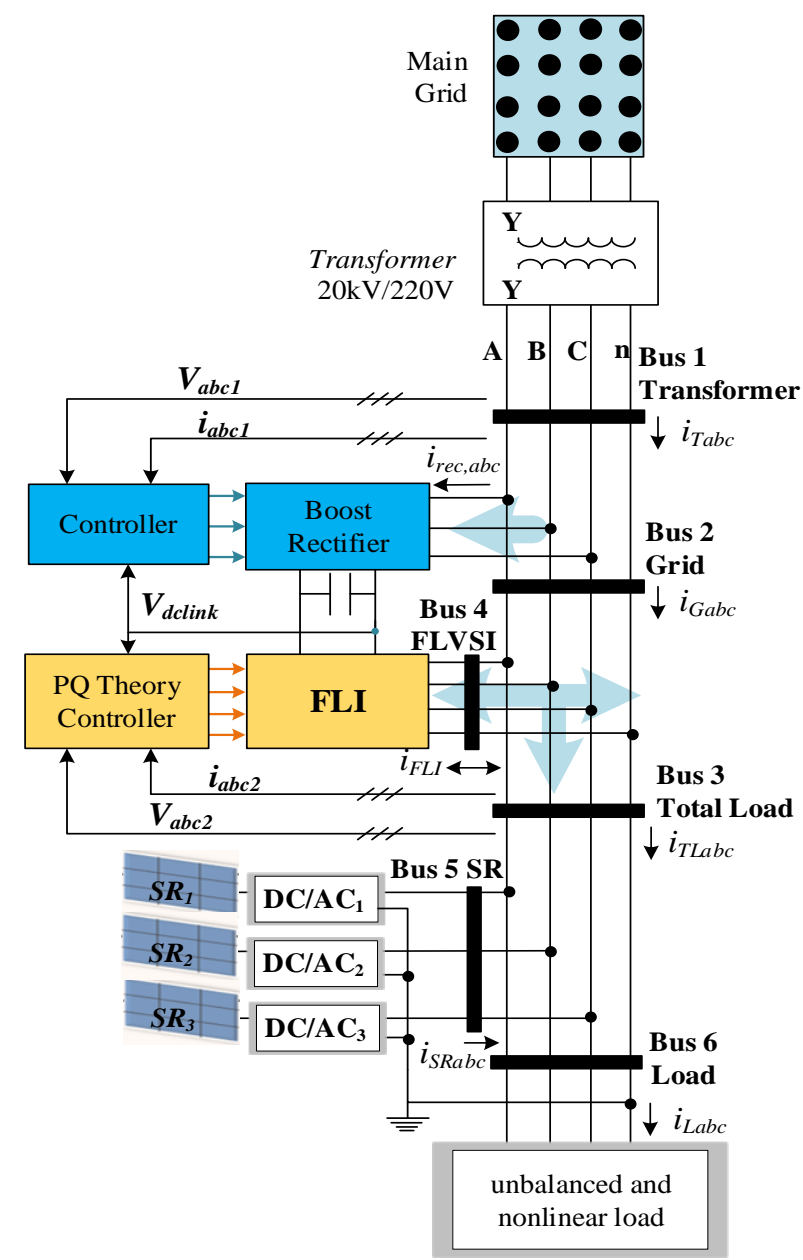

Figure. 2 MGRS System connected to distribution network with unbalanced and nonlinear loads

\section{Modeling of MGRS system which connected to a distribution network}

Fig. 2 revealed a grid diagram of the MGRS system connected to a low voltage distribution network with FLI. An FLI is installed between bus 1 (bus transformer) and bus 3 (bus total load). Transformer supplied FLI via a three-phase boost rectifier. There was one RS for each stage, and each $\mathrm{RS}$ represented the n-number of RS in the same phase. RS was designed based on research by Setiawan et al. [31].

This study used two approaches to load the system. It had an active load equal to the power demand and a changeable reactive load. The second load was a nonlinear harmonic generator. The nonlinear load included a three-phase diode bridge rectifier, an R-L load, and harmonics created by the RS system's inverter. Table 1 listed the parameters for each system component.

\subsection{Boost rectifier modeling}

A three-phase boost rectifier with Voltage Oriented 


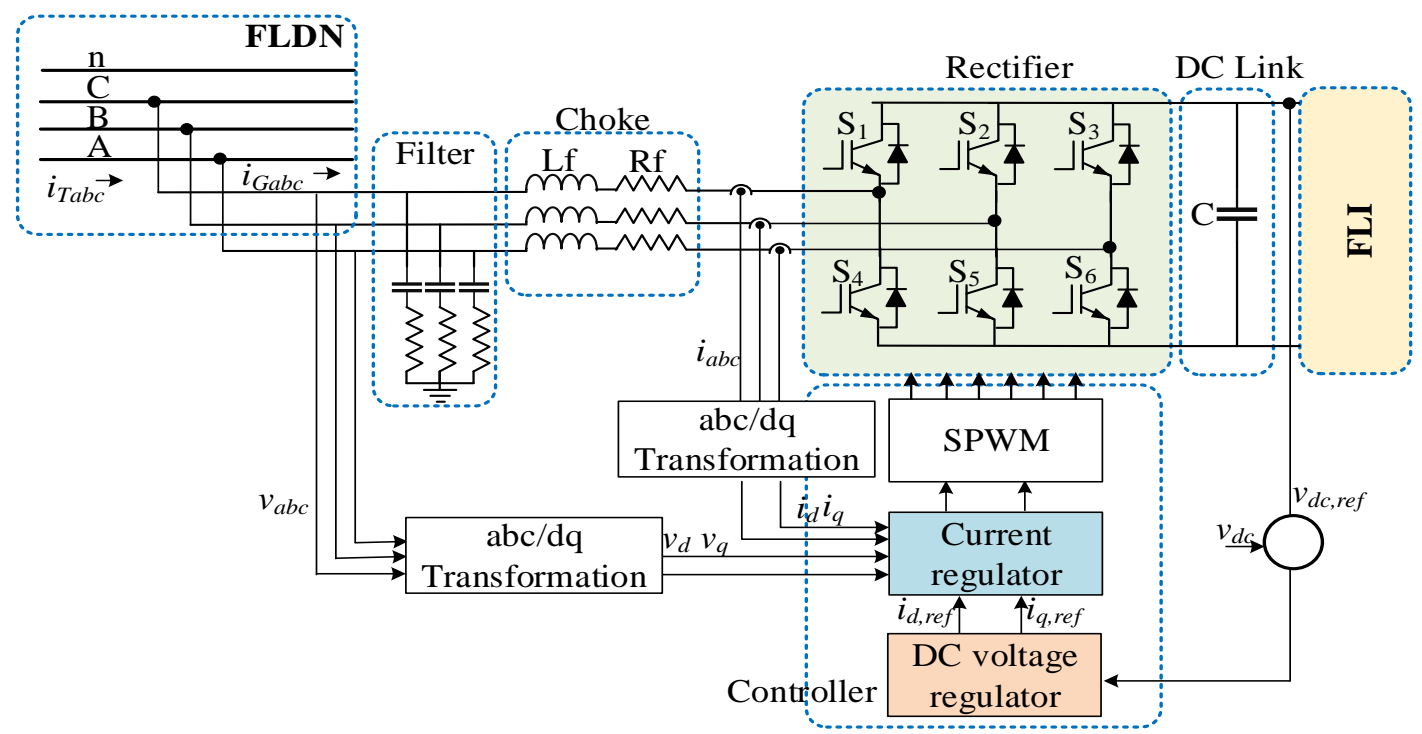

Figure. 3 Boost rectifier modeling in MGRS

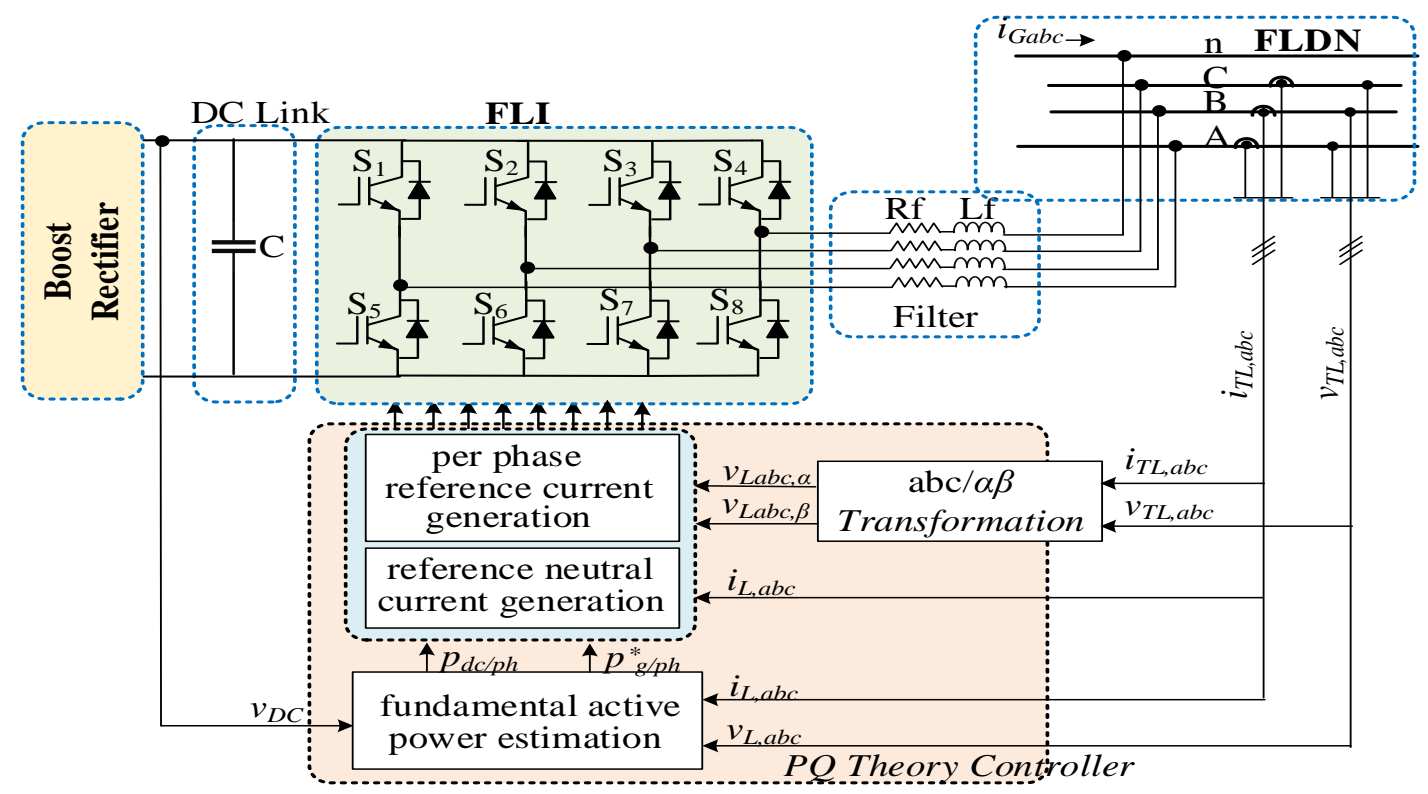

Figure. 4 FLI using PQ theory controller

Table 1. System parameter

\begin{tabular}{|c|c|}
\hline Parameters & Value \\
\hline \multicolumn{2}{|l|}{ Inverter } \\
\hline Rated input voltage $\left(V_{D C}\right)$ & $700 \mathrm{~V}$ \\
\hline Rated output voltage $\left(V_{A C}\right)$ & $220 \mathrm{~V}$ \\
\hline Frequency & $50 \mathrm{~Hz}$ \\
\hline \multicolumn{2}{|l|}{ Transformer } \\
\hline Rated input voltage & $20 \mathrm{kV}$ \\
\hline Rated output voltage & $380 \mathrm{~V}$ \\
\hline Frequency & $50 \mathrm{~Hz}$ \\
\hline Capacity & $630 \mathrm{kVA}$ \\
\hline
\end{tabular}

Control (VOC) feedforward control system was utilized in this research Fig. 3 displayed the rectifier's position and configuration in the system. A series of filters and choke-linked a rectifier to Four-Leg Distribution Network (FLDN) . The control system was comprised of a voltage and current regulator. The voltage regulator's primary function was to control DC link current and generate current reference $\left(i_{d}{ }^{*}\right)$. During the controller designing process, DC voltage alteration was assumed to be slower than DC current in a higher dynamic system [32]. Therefore, id current could trace the current reference correctly.

\subsection{Three-Phase FLI based on single-phase PQ theory}

Figs. 2 and 4 illustrate FLI with MGRS linked to a distribution network. The system is composed of a 


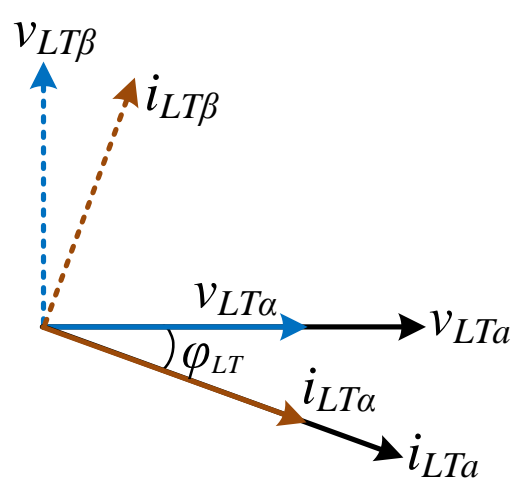

Figure. 5 Transformation diagram of the current signal and single-phase sinusoidal voltage to $\alpha-\beta$ coordinate

boost rectifier, a DC link, a filter, an FLI, and a controller. Direct current control and indirect current control techniques are often used in the current control mode of an inverter. Indirect current control mode, the resultant reference signal is employed as a current inverter. Indirect current control mode, the reference signal created is a current supply. Indirect current control was used in this study, and a controlling approach based on PQ theory was developed, as seen in Fig. 4. The controller was divided into active power estimation on each phase and a current reference generator.

\subsubsection{Fundamental Active Power Estimation}

\section{Voltage and current on $\alpha-\beta$ coordinate}

The three-phase PQ concept theory was extended to include single-phase systems [33]. A single-phase signal, according to this theory, may be described as an imaginer two-phase system produced by moving the phase $\pi / 2$ lead or $\pi / 2$ lag. The $\alpha \beta$ coordinate denoted a system with two phases. Thus, each voltage and current in a three-phase system may be regarded as independent of the others. These principles apply to three-phase systems that are balanced or unbalanced.

The main idea was to produce a fictitious orthogonal signal with a real current network and voltage value for each phase, as demonstrated by Fig. 5. The orthogonal signal was built by establishing actual voltage $\left(v_{T L}\right)$ and current $\left(i_{T L}\right)$ load as $\alpha$-axis components. In comparison, the lead signal of $\pi / 2$ or lag $\pi / 2$ was determined as the $\beta$-axis component. According to Eqs. (1) and (2), this investigation used $\pi / 2$ lead as a $\beta$-axis component.

$$
\begin{aligned}
& v_{T L \alpha}=v_{T L} ; v_{T L \beta}=v_{T L \alpha} \angle \pi / 2 \\
& i_{T L \alpha}=i_{T L} ; i_{T L \beta}=i_{T L \alpha} \angle \pi / 2
\end{aligned}
$$

The voltage load of $v_{T L a}, v_{T L b}$, and $v_{T L C}$ for a threephase system, at $\alpha-\beta$ coordinate, could be represented as $\pi / 2$ in equation number Eqs. (3-5).

$$
\begin{aligned}
& {\left[\begin{array}{l}
v_{T L a \alpha} \\
v_{T L a \beta}
\end{array}\right]=\left[\begin{array}{l}
v_{T L m} \sin (\omega t) \\
v_{T L m} \cos (\omega t)
\end{array}\right]} \\
& {\left[\begin{array}{l}
v_{T L b \alpha} \\
v_{T L b \beta}
\end{array}\right]=\left[\begin{array}{l}
v_{T L m} \sin (\omega t-2 \pi / 3) \\
v_{T L m} \cos (\omega t-2 \pi / 3)
\end{array}\right]} \\
& {\left[\begin{array}{l}
v_{T L c \alpha} \\
v_{T L c \beta}
\end{array}\right]=\left[\begin{array}{l}
v_{T L m} \sin (\omega t+2 \pi / 3) \\
v_{T L m} \cos (\omega t+2 \pi / 3)
\end{array}\right]}
\end{aligned}
$$

Shifting technique used $\pi / 2$ lead, current load for $i_{T L a}, i_{T L b}$, and $i_{T L C}$ phase at $\alpha \beta$ coordinate as displayed by Eqs. (6-8). Variables $v_{T L m}$ and $i_{T L m}$ represented current magnitude and total current load, respectively.

$$
\begin{aligned}
& {\left[\begin{array}{l}
i_{T L a \alpha} \\
i_{T L a \beta}
\end{array}\right]=\left[\begin{array}{l}
i_{T L m} \sin (\omega t)+\varphi_{T L} \\
i_{T L m} \cos \left(\omega t+\varphi_{T L}\right)
\end{array}\right]} \\
& {\left[\begin{array}{l}
i_{T L b \alpha} \\
i_{T L b \beta}
\end{array}\right]=\left[\begin{array}{l}
i_{T L m} \sin \left(\omega t+\varphi_{T L}-2 \pi / 3\right) \\
i_{T L m} \cos \left(\omega t+\varphi_{T L}-2 \pi / 3\right)
\end{array}\right]} \\
& {\left[\begin{array}{l}
i_{T L c \alpha} \\
i_{T L c \beta}
\end{array}\right]=\left[\begin{array}{l}
i_{T L m} \sin \left(\omega t+\varphi_{T L}+2 \pi / 3\right) \\
i_{T L m} \cos \left(\omega t+\varphi_{T L}+2 \pi / 3\right)
\end{array}\right]}
\end{aligned}
$$

\section{Reactive and active power based on single-phase PQ theory}

Based on the definition of three-phase PQ theory, in a balanced system, the instantaneous active power $\left(P_{\text {TLabc }}\right)$ and instantaneous reactive power $\left(Q_{\text {TLabc }}\right)$ component load as depicted in Eqs. (9) and (10).

$$
\begin{gathered}
P_{T L a b c}=v_{T L a b c \alpha} i_{T L a b c \alpha}+v_{T L a b c \beta} i_{T L a b c \beta} \\
Q_{T L a b c}=v_{T L a b c \alpha} i_{T L a b c \alpha}-v_{T L a b c \beta} i_{T L a b c \beta}
\end{gathered}
$$

$P_{T L a b c}$ and $Q_{T L a b c}$ above could be illustrated in a matrix below:

$$
\left[\begin{array}{l}
P_{T L a b c} \\
Q_{T L a b c}
\end{array}\right]=\left[\begin{array}{cc}
v_{T L a b c \alpha} & v_{T L a b c \beta} \\
-v_{T L a b c \beta} & v_{T L a b c \alpha}
\end{array}\right]\left[\begin{array}{l}
i_{T L a b c \alpha} \\
i_{T L a b c \beta}
\end{array}\right]
$$

This instantaneous power load consisted of DC and AC components. DC component was utilized as a fundamental active and reactive power generator $\left(P_{T L d c}, Q_{T L d c}\right)$. In contrast, the AC component was intended to act as an active and reactive harmonic 


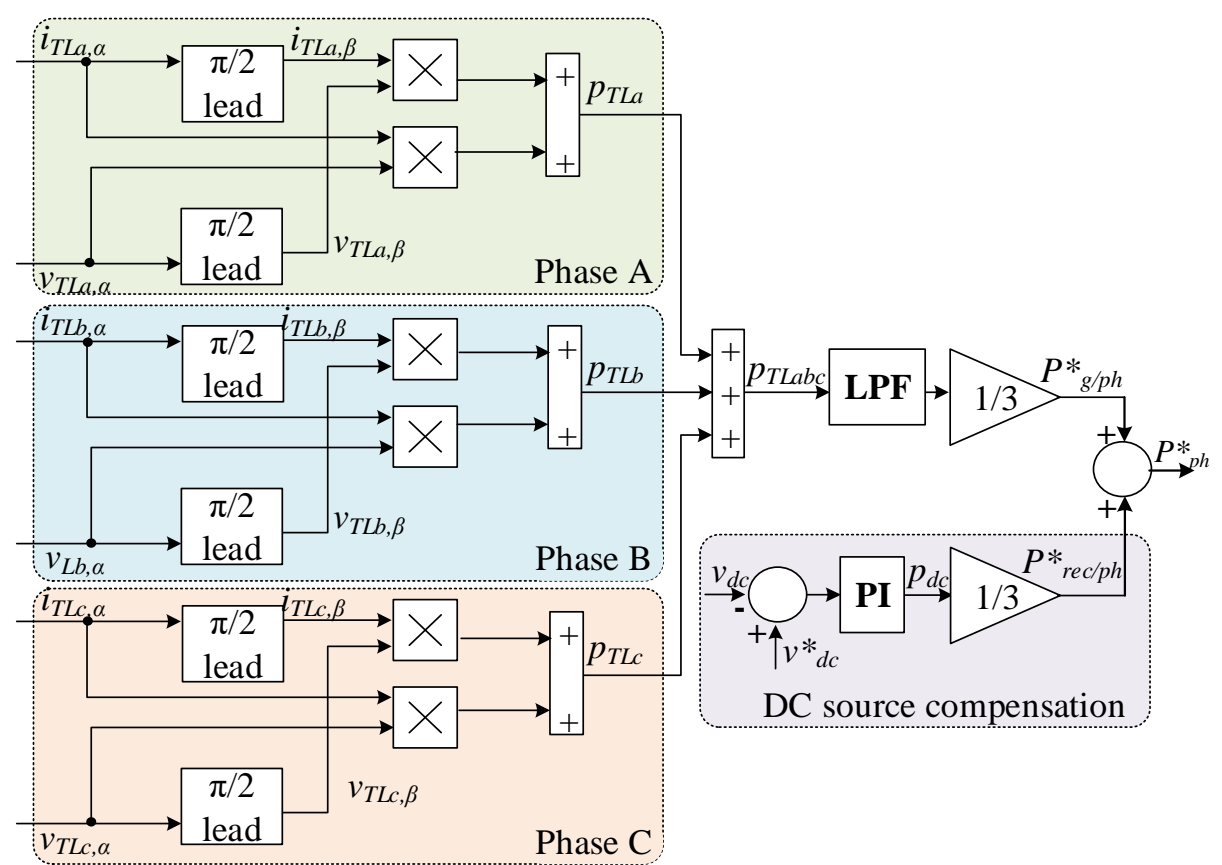

Figure. 6 Estimation block of active power for each stage using single-phase PQ theory

power supply ( $\left.P_{T L a c}, Q_{T L a c}\right)$ as displayed in Eqs. (12) and (13).

$$
\begin{gathered}
P_{T L a b c}=P_{T L a b c, d c}+P_{T L a b c, a c} \\
Q_{T L a b c}=Q_{T L a b c, d c}+Q_{T L a b c, a c}
\end{gathered}
$$

The total power load value was equal to the power supplied by the grid via a transformer. To avoid having issues with current transformer and voltage value did not have harmonic; transformer only supplied fundamental power load for each phase, including active power $\left(P_{T L a l}, P_{T L b l}, P_{T L c l}\right)$ and reactive power $\left(Q_{T L a l}, Q_{T L b l}, Q_{T L c l}\right)$. Therefore, instantaneous fundamental active power load had equal value with DC component power, as demonstrated by Eqs. (14-16), which was achievable with a low pass filter

$$
\begin{aligned}
& P_{T L a 1}=P_{T L a, d c} \\
& P_{T L b 1}=P_{T L b, d c} \\
& P_{T L c 1}=P_{T L c, d c}
\end{aligned}
$$

Active load demand and instantaneous fundamental reactive power load for every phase could not be equal or balanced because each stage pulled the current load independently. A balanced three-phase active load of the transformer was produced from an unbalanced load, which could be done by distributing the load equally to all transformer phases and FLI. Therefore, the transformer's total load was perceived as a balanced load; thus, each phase's grid power $\left(P^{*} g / p h\right)$ would have an exact value. Eqs. (17) and (18) revealed an instantaneous fundamental active power load calculation process for all three phases. The equation calculated the average value of power load and redistributed it to each transformer phase, so an equal value was achieved. This condition is shown in Fig. 6.

$$
\begin{aligned}
& P_{T L, \text { total }}=P_{T L a, 1}+P_{T L b, 1}+P_{T L c, 1} \\
& P_{g / p h}^{*}=\frac{P_{T L, t o t a l}}{3}
\end{aligned}
$$

\subsubsection{Calculation of current reference}

Eq. (17) showed the fundamental active power demand calculation, which each transformer stage must deliver to ensure balance. This equation was also used to find the required basic active total load equal to the transformer's total active power for each step. Also, by changing Eqs. (17) to (19), the transformer's instantaneous power may be determined. Supply voltage $\left(v_{G a b c}\right)$ has an equal value with load voltage $\left(v_{\text {Labc }}\right)$ because of its parallel connection. The transformer's instantaneous fundamental power value was acquired by calculating incoming power to load $\left(P^{*} G / p h\right)$ with the rectifier has consumed power $\left(P^{*}\right.$ rec/ph $)$ for every phase. $P^{*}$ recph was the total of every phase's active power taken from the source and rectified as a DC IEL source with constant dc-link output. 


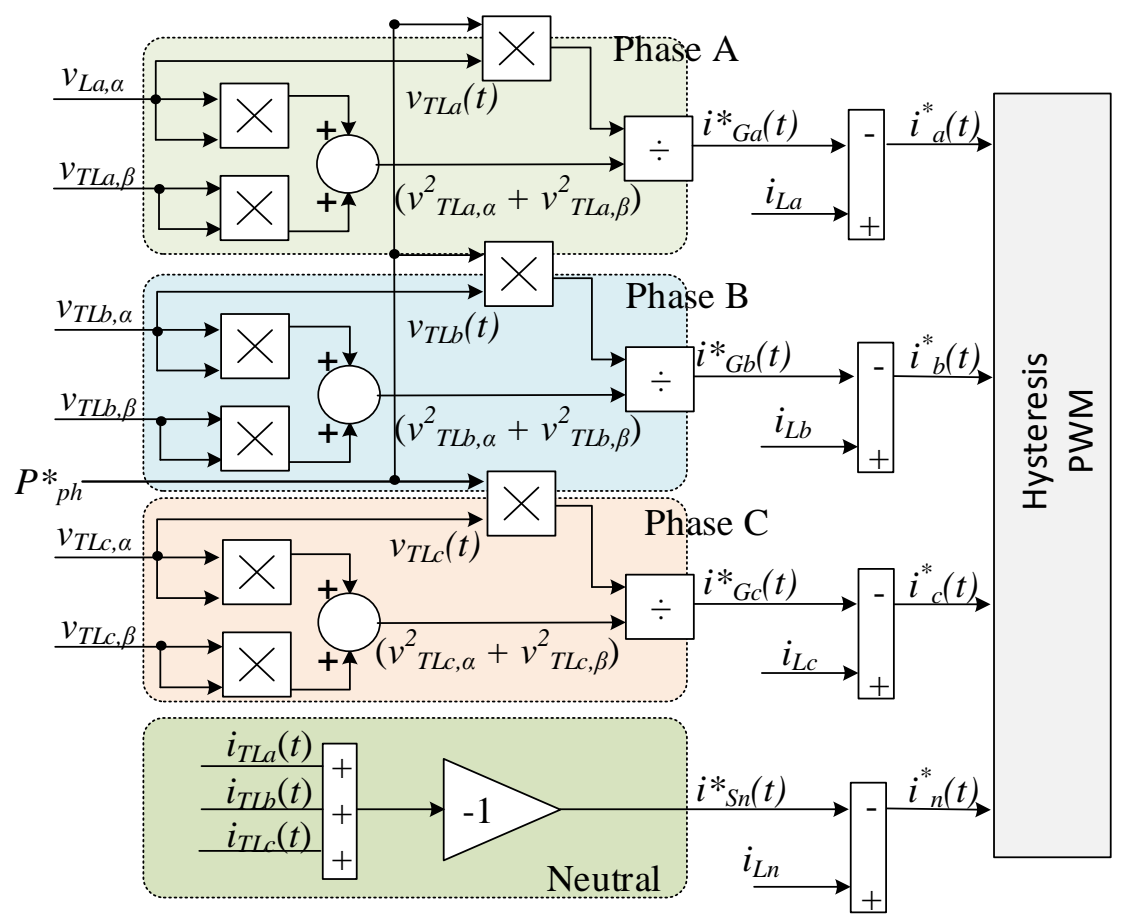

Figure. 7 Current reference calculation for each phase and neutral line

$$
\left[\begin{array}{c}
P_{G a b c} \\
Q_{G a b c}
\end{array}\right]=\left[\begin{array}{cc}
v_{G a b c \alpha} & v_{G a b c \beta} \\
-v_{G a b c \beta} & v_{G a b c \alpha}
\end{array}\right]\left[\begin{array}{l}
i_{G a b c \alpha} \\
i_{G a b c \beta}
\end{array}\right]
$$

The inverse of Eq. (19) can be used to obtain the compensation of the balanced three-phase system for the current reference $\left(i *_{G a b c}, \alpha, i *_{G a b c, \beta}\right)$ Eq. (20).

Reactive power $\left(Q_{L a}\right)$ had zero value because the installed transformer was not supplying demand from reactive power load.

$$
\left[\begin{array}{c}
i_{G a b c \alpha}^{*} \\
i_{G a b c \beta}^{*}
\end{array}\right]=\left[\begin{array}{cc}
v_{G a b c \alpha} & v_{G a b c \beta} \\
-v_{G a b c \beta} & v_{G a b c \alpha}
\end{array}\right]\left[\begin{array}{c}
P_{G / p h}^{*}+P_{r e c / p h}^{*} \\
0
\end{array}\right]
$$

Fig. 7 shows the calculation of current references calculation. The $\alpha$-axis current reference compensation represented instantaneous current source (transformer) from the matrix above because the $\alpha$-axis quantity was a real system. In comparison, the $\beta$-axis was a current reference compensation located at $\pi / 2$ lead of the real. So, each current reference could be explained in Eq. (21-23).

$$
\begin{aligned}
& i_{G a}^{*}(t)=\frac{V_{T L a \alpha}(t)}{v_{T L a \alpha}^{2}+v_{T L a \beta}^{2}}\left[P_{G / p h}^{*}+P_{r e c / p h}^{*}\right] \\
& i_{G b}^{*}(t)=\frac{V_{T L b \alpha}(t)}{v_{T L b \alpha}^{2}+v_{T L b \beta}^{2}}\left[P_{G / p h}^{*}+P_{r e c / p h}^{*}\right] \\
& i_{G c}^{*}(t)=\frac{V_{T L c \alpha}(t)}{v_{T L c \alpha}^{2}+v_{T L c \beta}^{2}}\left[P_{G / p h}^{*}+P_{r e c / p h}^{*}\right]
\end{aligned}
$$

The expected current flowed through the neutral line $\left(i_{L n}\right)$ was the total sum of all current phases without calculating the real neutral current. The reverse value of $i_{L n}$ was a neutral current reference signal $\left(i *_{G n}\right)$, which is explained in Eqs. (24) and (25).

$$
\begin{aligned}
& P_{T L n}(t)=P_{T L a}(t)+P_{T L b}(t)+P_{T L c}(t) \\
& i_{G n}^{*}(t)=-i_{T L, n}(t)
\end{aligned}
$$

Block estimation of active power was estimated by instantaneously calculating each phase's active power average. The last block, illustrated by Fig. 7, was a controller of the reference current signal generator. This controller was divided into the current reference of every phase and the neutral current. The $i{ }^{*}{ }_{s h}$ current was the current reference that must be subtracted with the value of an actual current load, and the result from this calculation was a reference signal for the IEL switch.

\section{Proposed OCNN with the selected input}

Fig. 2 shows the model of the MGRS system connected to the distribution network with unbalanced loads, while Figs. 6 and 7 represent the control strategy using the PQ theory. The proposed controller is built on the classic inverter controller. This control system is modified using OCNN, as shown in Fig. 8.

OCNN is composed of two layers: a hidden layer 


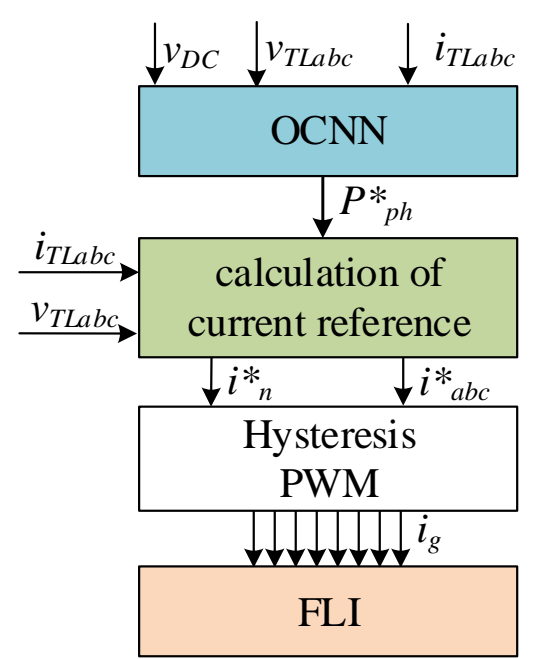

Figure. 8 OCNN control for FLI

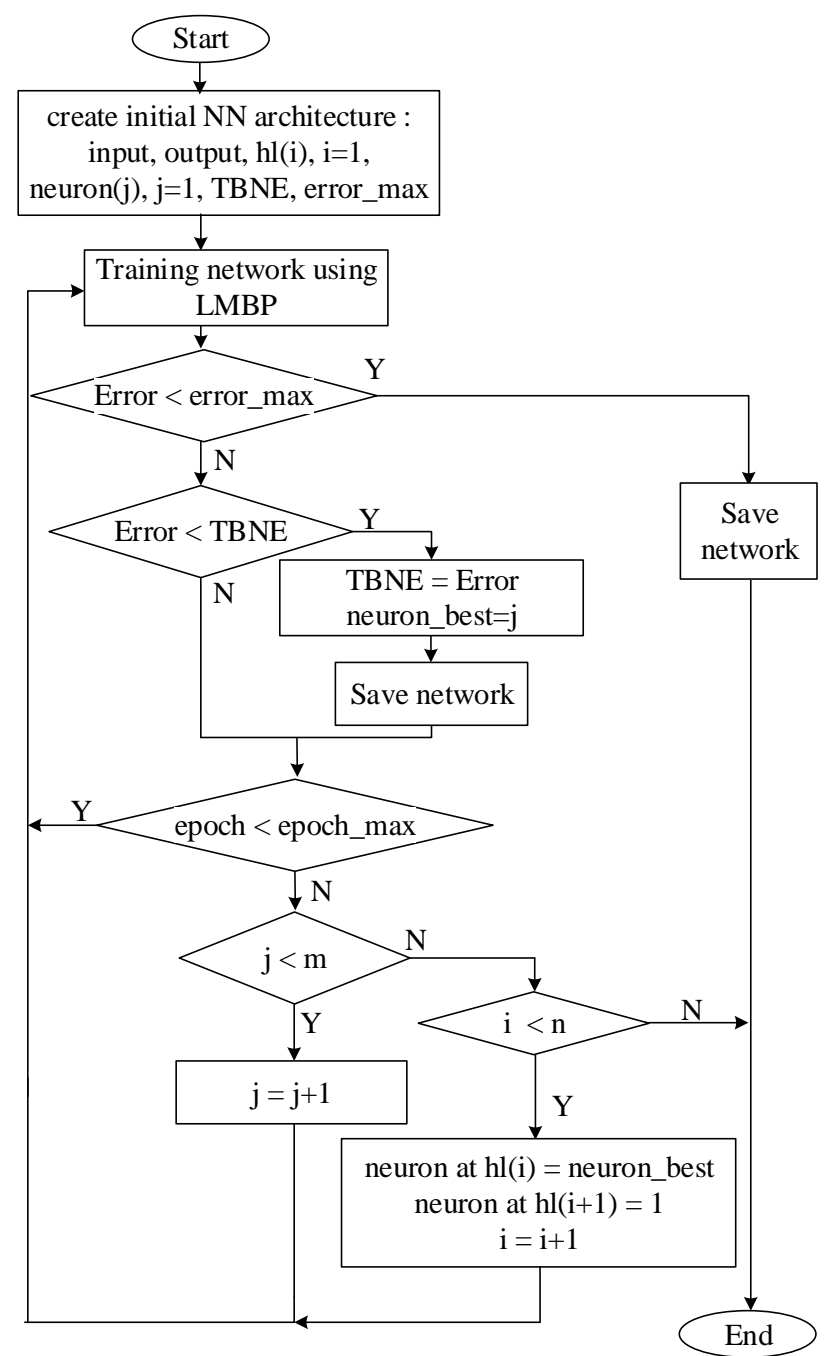

Figure. 9 Current reference calculation for each phase and neutral line

and an output layer. The first layer contains $n$ nonlinear transfer functions buried levels. Each layer of the hidden layer is limited to a certain number of neurons $(\mathrm{m})$. The training phase spanned multiple epochs. At each epoch, the training error value is compared to the memory-stored temporary best network error (TBNE). Thus, by training with a large amount of data, the capacity of an OCNN network can adjust to handle problems. Fig. 9 depicts the OCNN generalization flow diagram.

\subsection{Input}

The size of the input layer is equal to the sum of the measurements and the switches. The size of the output layer is equal to the number of bus voltage magnitudes or line current magnitudes. The candidate input for OCNN is voltage: $v_{d c}$ and $v_{T L a b c}\left(v_{T l a}, v_{T l b}\right.$, $v_{T L C}$, and current $i_{T l a b c}\left(i_{T l a}, i_{T l b}, i_{T L C}\right)$, while the OCNN output signal is the reference power $P^{*}{ }_{p h}$.

The usage of LMNN involves a significant investment of time and resources, particularly during the training process. If the number of input variables is enormous, this condition will take an increasing amount of time. As a result, the selection of OCNN input candidates is carried out in this paper using Person correlation analysis. Two criteria are taken into account while employing the correlation model: the nature of the link and the availability of lengthy data. Pearson correlation coefficients vary between 1 and 1. A number near -1 implies a negative dependence, whereas a value near -1 shows a positive connection. There is no linear dependency when the coefficient approaches zero.

\subsection{Architecture}

Fig. 10 illustrates the OCNN architectural model, in which the number of hidden layers and neurons within them is flexible up to a given value. The maximum number of hidden layers in this work is three, with each layer containing a maximum of 25 neurons. Each neuron in the hidden layer has a tansig

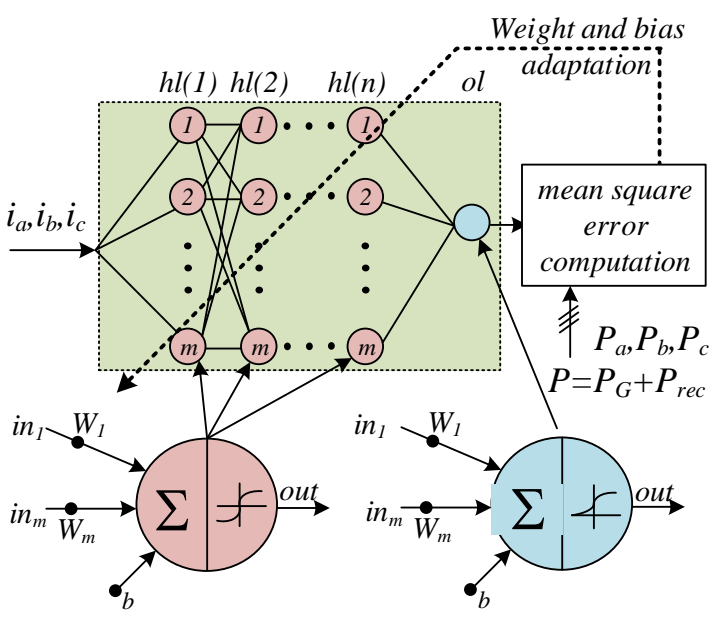

Figure. 10 Neural networks for PQ theory architecture 
Table 2. RMS data of input candidate and output OCNN

\begin{tabular}{|c|c|c|c|c|c|c|c|c|c|}
\hline No & ime (s) & $v_{T l a}($ volt $)$ & $v_{T L b}($ volt $)$ & $v_{T L c}($ volt $)$ & $v_{d c}($ volt $)$ & $i_{\text {iTla }}$ (A) & $i_{T L b}(\mathbf{A})$ & $i_{T L c}(\mathbf{A})$ & $P *_{p h}(\mathrm{~W})$ \\
\hline 1 & & & & & & & & & .9137 \\
\hline 2 & & & & & & & & & \\
\hline 3 & 0.2000079 & 215.1960 & 204.9620 & 211.9277 & 696.2911 & & 34.4890 & 33.8806 & 10196.7668 \\
\hline 4 & 0.2000098 & 215.1960 & 204.9621 & 211.9280 & 696.2913 & & & 33.8809 & 10196.7138 \\
\hline 5 & 0.2000159 & 15.1958 & 204.9615 & 211.9297 & 696.2886 & 20.4523 & 34.4885 & 33.8827 & 5756 \\
\hline 6 & & & & & 696.2873 & & & 33.8837 & 10196.4830 \\
\hline 7 & 0.2000228 & 215.1957 & 204.9612 & 211.9315 & 696.2867 & 20.4524 & 34.4880 & 33.8844 & 10196.4101 \\
\hline 8 & & & & & & & & & \\
\hline 9 & 0.2000278 & 215.1955 & 204.9604 & 211.9332 & 696.2884 & 20.4525 & 34.4877 & 33.8858 & 10196.2641 \\
\hline$\vdots$ & $\vdots$ & $\vdots$ & $\vdots$ & $\vdots$ & $\vdots$ & $\vdots$ & $\vdots$ & $\vdots$ & $\vdots$ \\
\hline 105682 & & & 204.6836 & 212.6838 & 697.2063 & 39.2743 & 48.2653 & 44.8199 & 15297.3254 \\
\hline 105683 & 0.4999985 & & 204.6830 & 212.6843 & 697.2132 & 39.2743 & 48.2651 & 44.8199 & 15297.1986 \\
\hline 105684 & 0.5000000 & 214.5375 & 204.6825 & 212.6849 & 697.2231 & 39.2742 & 48.2650 & 44.8198 & 15297.0710 \\
\hline
\end{tabular}

activation function, whereas the output layer uses a logsig activation function. The adaptation of the weight (W) and bias (b) in OCNN is initially based on the mean square error (MSE) and is then followed by the execution of the Levenberg-Marquardt backpropagation (LMBP) algorithm.

According to Section 3.1's study, several variables are important in regulating FLI utilizing PQ theory. Sets may be used to express it $Z=\{z 1, z 2, \ldots$, $z p\}$. The nonlinear connection between the output value $\mathrm{Y}$ and the primary factors $\mathrm{Z}$ is denoted by Eq. (26), where $W_{0}$ represents the correlation matrix of the space containing the primary factors.

$$
Y=f\left(W_{0} Z\right)
$$

By substituting it into the Levenberg-Marquardt method, a mathematical model for neural networks is constructed. The weight update process and bias will be adjusted directly utilizing negative gradient descent in this technique. Eq. (27) illustrates this algorithm's usage of the Hessian (H) matrix approximation. The algorithm's gradient calculation expresses in Eq. (28), where $e(w)$ denotes a network error vector.

$$
\begin{aligned}
& \mathrm{H}(w)=J(w)^{T} J(w) \\
& \mathrm{g}(w)=J(w)^{T} e(w)
\end{aligned}
$$

$J(w)$ is a Jacobian matrix containing the first derivative of the network error, which is shown in Eq. (29).

$$
J(w)=\left[\begin{array}{cccc}
\frac{\partial e_{1}(w)}{\partial w_{1}} & \frac{\partial e_{1}(w)}{\partial w_{2}} & \cdots & \frac{\partial e_{1}(w)}{\partial w_{n}} \\
\frac{\partial e_{1}(w)}{\partial w_{1}} & \frac{\partial e_{2}(w)}{\partial w_{2}} & \cdots & \frac{\partial e_{2}(w)}{\partial w_{n}} \\
\vdots & \vdots & & \vdots \\
\frac{\partial e_{l}(w)}{\partial w_{1}} & \frac{\partial e_{l}(w)}{\partial w_{2}} & \cdots & \frac{\partial e_{l}(w)}{\partial w_{n}}
\end{array}\right]
$$

The Levenberg-Marquardt algorithm behaves as Newton is expressed by the Eqs. (30) and (31).

$$
\begin{aligned}
& \mathrm{w}(k+1)=w(k)+\Delta w(k) \\
& \Delta \mathrm{w}=-\left[\mathrm{J}^{T}(w) J(w)\right]^{-1} \mathrm{~J}(w) e(w)
\end{aligned}
$$

where $w(k+1)$ is a new weight as gradient and current weight function $w(k)$ calculated using the Newton algorithm.

\section{Results and discussion}

To evaluate the suggested single-phase PQ theory based on the OCNN method's efficacy, the FLI and MGRS models (see Fig. 2) were simulated and confirmed using Matlab/Simulink. The OCNN's results were compared to those of a different configuration of an LMNN. The configurations 2525-25, 23-24-25, and 25-24-23 were chosen for the LMNN designs.

\subsection{Input analysis}

Table 2 contains the input candidates and output data for OCNN. The total load voltage and current 
Table 3. Pearson correlation result

\begin{tabular}{|c|c|}
\hline variable & $\boldsymbol{r}$ \\
\hline $\boldsymbol{v}_{T l a}$ & -0.0082 \\
\hline $\boldsymbol{v}_{T l b}$ & 0.0682 \\
\hline $\boldsymbol{v}_{T l c}$ & 0.1135 \\
\hline $\boldsymbol{v}_{\boldsymbol{d}}$ & 0.3128 \\
\hline $\boldsymbol{i}_{\boldsymbol{a}}$ & 0.9872 \\
\hline $\boldsymbol{i}_{\boldsymbol{b}}$ & 0.9308 \\
\hline $\boldsymbol{i}_{\boldsymbol{c}}$ & 0.9281 \\
\hline
\end{tabular}

RMS values, the DC link voltage, and the DC link voltage are all possible input candidates. The output of OCNN serves as the reference active power. The Pearson correlation statistical method can determine which input candidates have the most significant influence and are most closely related to the output [30]. If the Pearson correlation coefficient ( $r$ ) is more than 0.5 , the pair is highly correlated. The total data used is 105684 data simulations beginning at $0.2 \mathrm{~s}$ and ending at $0.5 \mathrm{~s}$.

As shown in Table 3, the Pearson correlation coefficient between series RMS current and reference active power is statistically significant, exceeding 0.9 . On the other hand, there was no statistically significant association between the RMS voltage, the dc-link voltage, and reference active power. As a result, the OCNN receives only the current value as an input.

\subsection{MSE evaluation in OCNN}

Utilizing the OCNN algorithm discussed previously, it is feasible to simulate data with predefined input and output/target data. The simulation begins with a single neuron and a hidden layer and progresses to the maximum feasible number of hidden layers.

According to Table 4, the mse derived from simulation results for the first hidden layer is 0.0048 , the minimum value attained when the layer has 24 neurons. As a result, when the network adds a second hidden layer, it uses the same amount of neurons as the first hidden layer. When the second hidden layer contains 25 neurons, the minimum mse value for the second hidden layer is 0.0011 .

The third hidden layer is formed using the OCNN structure of the first hidden layer, which has 24 neurons, and the OCNN structure of the second hidden layer contains 25 neurons. When 22 neurons in the third hidden layer were used, the lowest mse value obtained was 0.0001 . As a result, $24-25-22$ is the optimal neuronal configuration for this OCNN network.
The MSE values for LMNN configurations 2324-25, 25-24-23, and 25-25-25 are 0.00025, 0.00054, and 0.00018 , respectively.

After completing the OCNN and LMNN training sessions, the network results are applied to the FLI system on the RS array connected to the distribution network. This is performed to measure the controller's performance, particularly under transient conditions.

\subsection{OCNN under the transient operation of an FLI}

The output of the RS was intermittent; as a result, the generated power fluctuated in response to the presence of solar rays. The total load, or the combination of load and RS, was unbalanced and fluctuated in this case. Dynamic irradiation was used to represent fluctuating RS, as illustrated in Fig. 11. With this figure as a reference, the function for each irradiation can be described as Eqs. (32-34).

Table 4. MSE value for each neuron and hidden layer

\begin{tabular}{|c|c|c|c|c|c|}
\hline \multicolumn{2}{|c|}{ Hidden Layer 1} & \multicolumn{2}{|c|}{ Hidden Layer 2} & \multicolumn{2}{|c|}{ Hidden Layer 3} \\
\hline neuron & mse & neuron & mse & neuron & mse \\
\hline 1 & 0.0286 & 1 & 0.0041 & 1 & 0.0020 \\
\hline 2 & 0.0239 & 2 & 0.0041 & 2 & 0.0018 \\
\hline 3 & 0.0192 & 3 & 0.0037 & 3 & 0.0014 \\
\hline 4 & 0.0152 & 4 & 0.0031 & 4 & 0.0017 \\
\hline 5 & 0.0132 & 5 & 0.0028 & 5 & 0.0017 \\
\hline 6 & 0.0133 & 6 & 0.0029 & 6 & 0.0010 \\
\hline 7 & 0.0118 & 7 & 0.0018 & 7 & 0.0011 \\
\hline 8 & 0.0115 & 8 & 0.0018 & 8 & 0.0011 \\
\hline 9 & 0.0095 & 9 & 0.0021 & 9 & 0.0009 \\
\hline 10 & 0.0099 & 10 & 0.0016 & 10 & 0.0009 \\
\hline 11 & 0.0104 & 11 & 0.0023 & 11 & 0.0007 \\
\hline 12 & 0.0072 & 12 & 0.0018 & 12 & 0.0007 \\
\hline 13 & 0.0077 & 13 & 0.0018 & 13 & 0.0007 \\
\hline 14 & 0.0075 & 14 & 0.0016 & 14 & 0.0005 \\
\hline 15 & 0.0075 & 15 & 0.0015 & 15 & 0.0011 \\
\hline 16 & 0.0068 & 16 & 0.0015 & 16 & 0.0015 \\
\hline 17 & 0.0079 & 17 & 0.0015 & 17 & 0.0004 \\
\hline 18 & 0.0062 & 18 & 0.0022 & 18 & 0.0007 \\
\hline 19 & 0.0065 & 19 & 0.0012 & 19 & 0.0005 \\
\hline 20 & 0.0069 & 20 & 0.0016 & 20 & 0.0009 \\
\hline 21 & 0.0066 & 21 & 0.0015 & 21 & 0.0010 \\
\hline 22 & 0.0049 & 22 & 0.0016 & 22 & 0.0001 \\
\hline 23 & 0.0063 & 23 & 0.0013 & 23 & 0.0007 \\
\hline 24 & 0.0048 & 24 & 0.0016 & 24 & 0.0008 \\
\hline 25 & 0.0049 & 25 & 0.0011 & 25 & 0.0005 \\
\hline
\end{tabular}




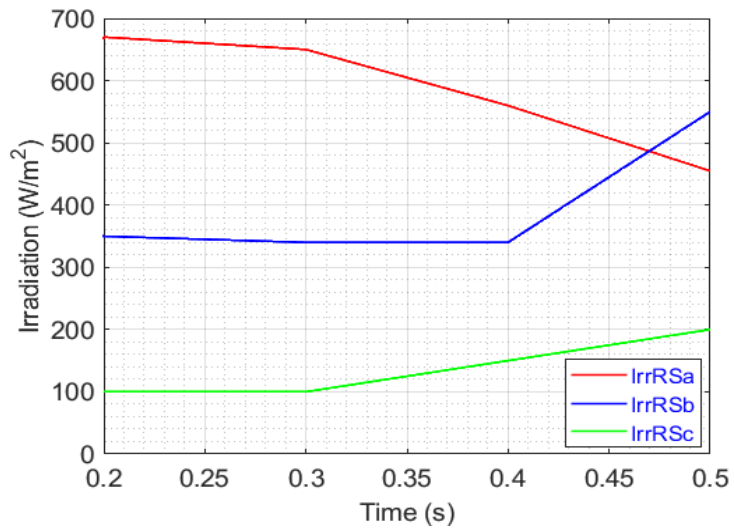

Figure. 11 Irradiance under a fluctuating condition

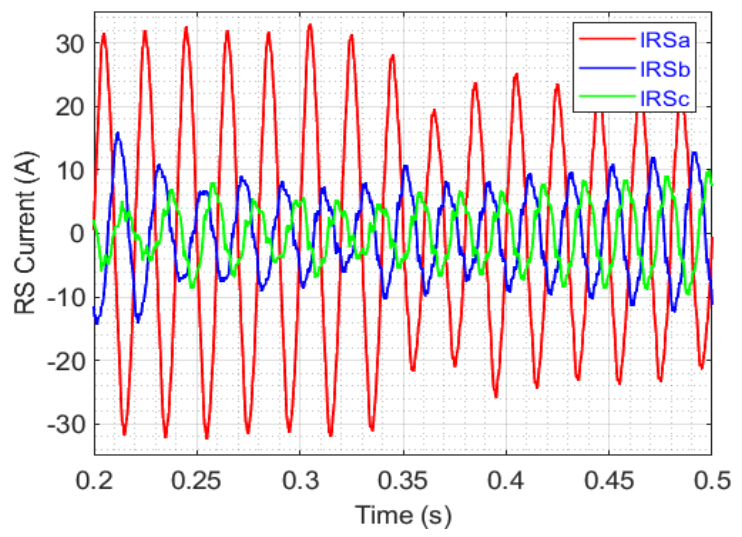

Figure. 12 RS current injection

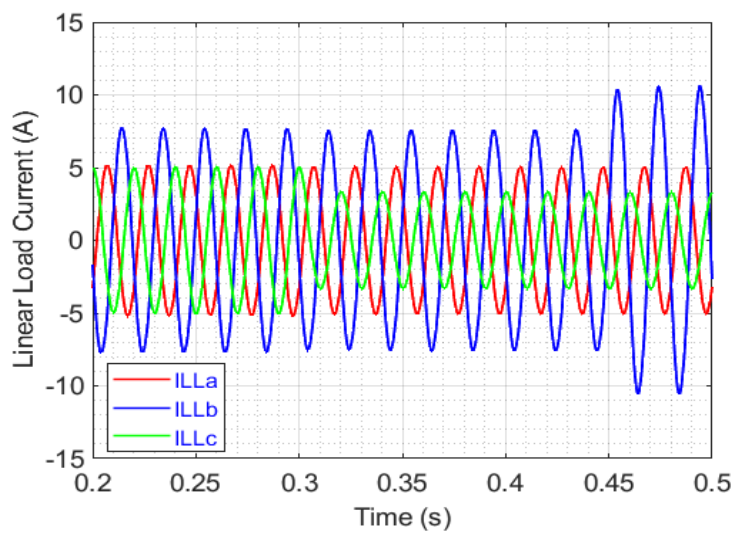

Figure. 13 Linear load current

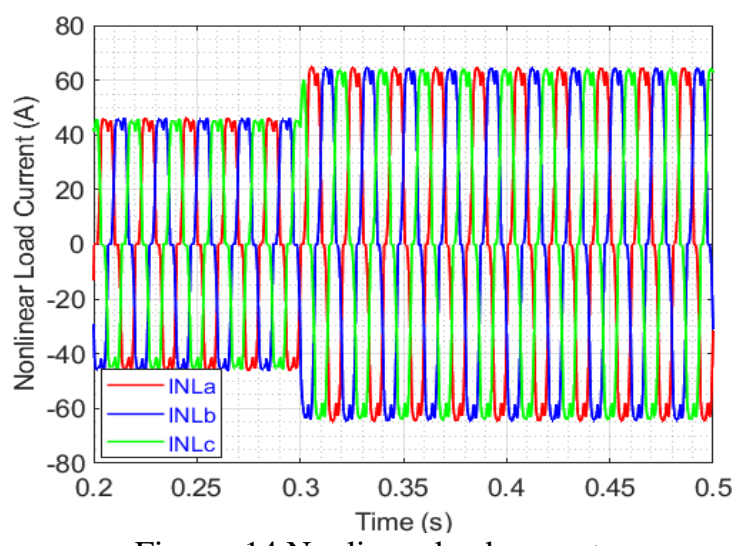

Figure. 14 Nonlinear load current
Table 5. Linear load parameter

\begin{tabular}{|c|c|c|c|}
\hline \multirow{2}{*}{ Phase } & \multirow{2}{*}{ Initial Load } & $\begin{array}{c}|c| \\
\text { time } \\
\text { (s) }\end{array}$ & Load \\
\hline A & $650 \mathrm{~W}, 500 \mathrm{VAr}$ & 0.5 & $1050 \mathrm{~W}, 600 \mathrm{VAr}$ \\
\hline B & $900 \mathrm{~W}, 900 \mathrm{VAr}$ & 0.45 & $1300 \mathrm{~W}, 1200 \mathrm{VAr}$ \\
\hline $\mathrm{C}$ & $700 \mathrm{~W}, 400 \mathrm{VAr}$ & 0.3 & $450 \mathrm{~W}, 300 \mathrm{VAr}$ \\
\hline
\end{tabular}

$$
\begin{aligned}
& \operatorname{Irr}_{A}(x)= \begin{cases}-200 x+700, & 0.2 \leq x \leq 0.3 \\
-985 x+950, & 0.3<x \leq 0.5\end{cases} \\
& \operatorname{Irr}_{B}(x)=\left\{\begin{array}{rr}
-100 x+370, & 0.2 \leq x \leq 0.3 \\
340, & 0.3<x \leq 0.4 \\
2100 x-500, & 0.4<x \leq 0.5
\end{array}\right. \\
& \operatorname{Irr}_{C}(x)=\left\{\begin{array}{rr}
100, & 0.2 \leq x \leq 0.3 \\
500 x-50, & 0.3<x \leq 0.5
\end{array}\right.
\end{aligned}
$$

The maximum and minimum irradiation values are $670 \mathrm{~W} / \mathrm{m} 2$ and $305 \mathrm{~W} / \mathrm{m} 2$ for phase $\mathrm{A}, 600 \mathrm{~W} / \mathrm{m} 2$ and $340 \mathrm{~W} / \mathrm{m} 2$ for phase $\mathrm{B}$, and $600 \mathrm{~W} / \mathrm{m} 2$ and 100 $\mathrm{W} / \mathrm{m} 2$ for phase C, respectively. Each SR injects RS current into the distribution network in response to the received irradiation. This is seen in Fig. 12.

Figs. 13-15 illustrate the current load value for each phase, whether for linear load, nonlinear load, or total load. In stages A and B of the linear load phase, the load was raised. In phase A, the inductive load was increased incrementally from $650 \mathrm{~W}$, 500 Var to $1050 \mathrm{~W}, 600 \mathrm{Var}$ at $0.5 \mathrm{~s}$. In phase B, the inductive load was increased from $900 \mathrm{~W}, 900 \mathrm{VAr}$ at $0.45 \mathrm{~s}$ to $1300 \mathrm{~W}, 1200 \mathrm{VAr}$. At $\mathrm{t}=0.3 \mathrm{~s}$, the load was reduced to $450 \mathrm{~W}, 300 \mathrm{VAr}$ in phase C. Table 5 summarizes all changes.

At 0.3 seconds, the R-L load at the rectifier output (nonlinear load) was changed from $10 \Omega$ and $5 \mathrm{mH}$ to $6.66 \Omega$ and $2.5 \mathrm{mH}$.

Figs. 15 and 16 depicted the grid current before and after applying FLI when loads and RS current injection were varied and unbalanced. Interestingly, based on these figures, the suggested controller could handle the Point of Common Coupling's (PCC's) current grid. Even when a very unbalanced and fluctuated harmonic affected the total load current, the current grid value stayed balanced. Thus, FLI could provide an unbalanced harmonic current to the grid without affecting PCC's voltage.

Changes in load or RS injection current cause adjustment in the value of the reference signal. Because the load pulled current unbalance, the value 
of In neutral current reference was not zero,

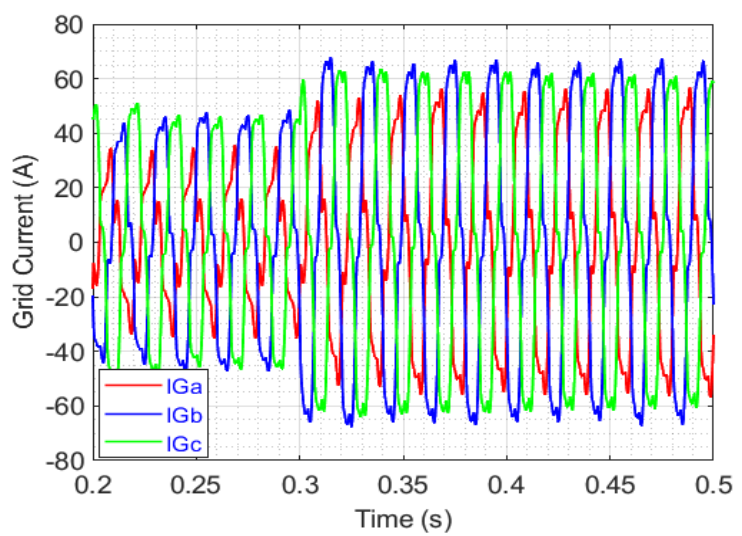

Figure. 15 Grid current before applying FLI

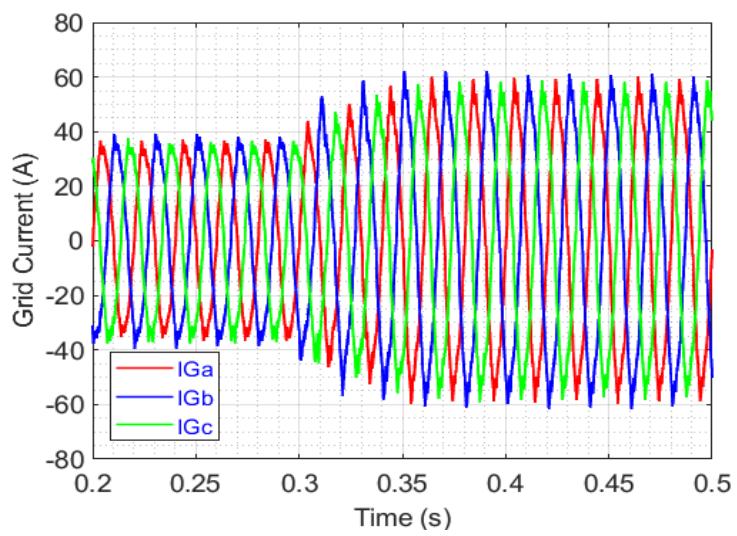

Figure. 16 Grid current after applying FLI

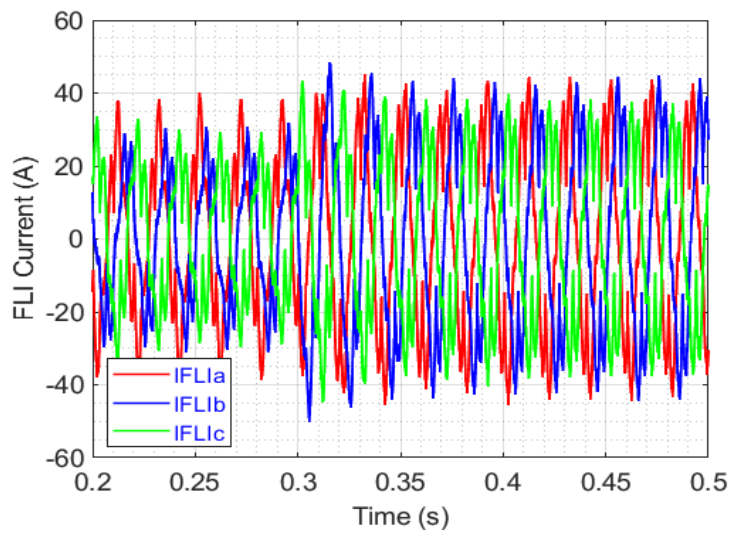

Figure. 17 FLI current

following calculations described in Eqs. (19-23). As illustrated in Figure 16, the PWM hysteresis block instructs the FLI to inject or withdraw current in response to the reference current. The injection current is depicted in Fig. 17.

\subsection{PCU and THDi}

The grid current compensation value determined by the OCNN controller is calculated by the current unbalanced and the THDi. The results are compared to those obtained when the LMNN was used previously.

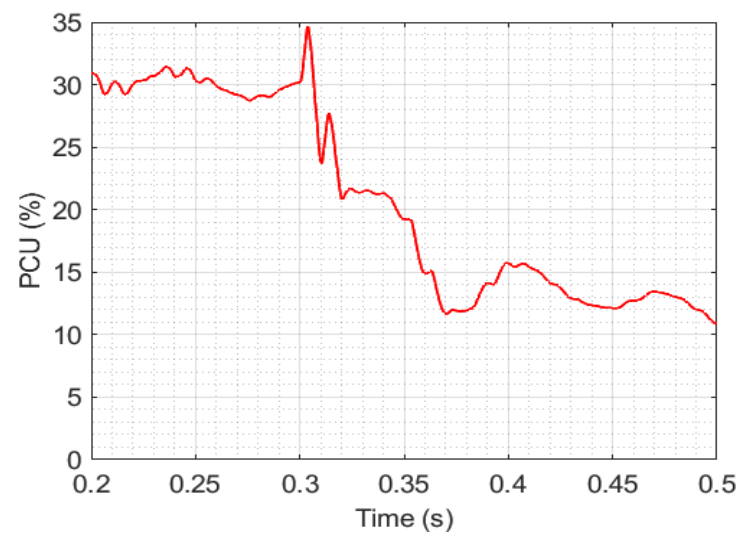

Figure. 18 PCU before applying FLI

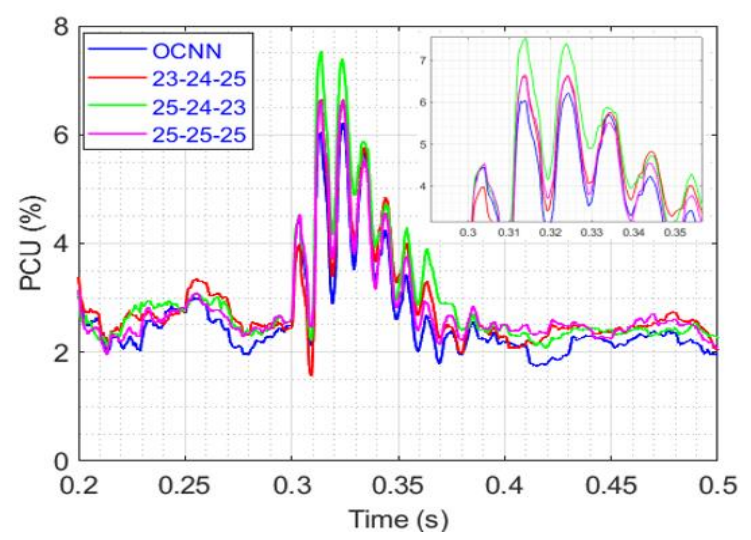

Figure. 19 PCU of the OCNN compared to LMNN

The current unbalance degree calculation was based on the ANSI/IEEE Std 241-1990 [12]. Unbalanced was calculated by comparing the maximum deviation value of the average of threephase current. This value was stated as percent current unbalance (PCU), demonstrated in Eq. (26).

$$
P C U=\frac{\text { Maximum Deviationfrom average current }}{\text { Average of three phase current }}
$$

Figs. 18 and 19 illustrated the computation process of PCU, which occurred during irradiation and load changes. Peak PCU's total load value reached $34.68 \%$. After the proposed controlling system was implemented, grid PCU became $6.22 \%$ or decreased by $82.06 \%$.

When the load and injection current RS vary, not only is the PCU unsteady, but the grid current's THDi also varies, as illustrated in Figures 20 to 25. Before administering FLI, the average THDi was $20.45 \%$ (Phase A), $14.02 \%$ (Phase B), and $14.48 \%$ (Phase C) (Phase $\mathrm{C}$ ). When the OCNN controller was used, this average value was reduced to $6.73 \%$ (Phase $\mathrm{A}$ ), 7.33\% (Phase B), and 6.63\% (Phase C).

The PCU calculation and THDi graph for various ANN controllers are shown in Figs. 19, 21, 23, and 
25, including the preferred technique. All control strategies employed enhance the quality of existing

Table 6. PCU and THDi of grid current

\begin{tabular}{|l|r|r|r|r|r|r|r|r|r|r|r|r|}
\hline & \multicolumn{4}{|c|}{ PCU (\%) } & \multicolumn{3}{c|}{ THDi Phase A (\%) } & \multicolumn{2}{c|}{ THDi Phase B (\%) } & \multicolumn{3}{c|}{ THDi Phase C (\%) } \\
\cline { 2 - 15 } & Peak & Trough & Mean & Peak & Trough & Mean & Peak & Trough & Mean & Peak & Trough & Mean \\
\hline No FLI & 34.68 & 10.89 & 20.71 & 32.25 & 15.24 & 20.45 & 19.15 & 11.97 & 14.02 & 21.24 & 12.95 & 14.48 \\
\hline OCNN & 6.22 & 1.73 & 2.62 & 10.87 & 5.28 & 6.73 & 13.81 & 5.75 & 7.33 & 10.83 & 5.58 & 6.63 \\
\hline $23-24-25$ & 6.65 & 1.56 & 2.89 & 11.15 & 5.35 & 7.00 & 14.18 & 6.41 & 7.62 & 11.18 & 5.50 & 6.82 \\
\hline $25-24-23$ & 7.53 & 7.53 & 2.98 & 11.49 & 11.50 & 7.14 & 14.54 & 14.54 & 7.72 & 11.45 & 11.45 & 6.85 \\
\hline $25-25-25$ & 6.62 & 1.95 & 2.85 & 11.64 & 5.39 & 6.96 & 12.93 & 6.12 & 7.61 & 11.04 & 5.27 & 6.79 \\
\hline
\end{tabular}

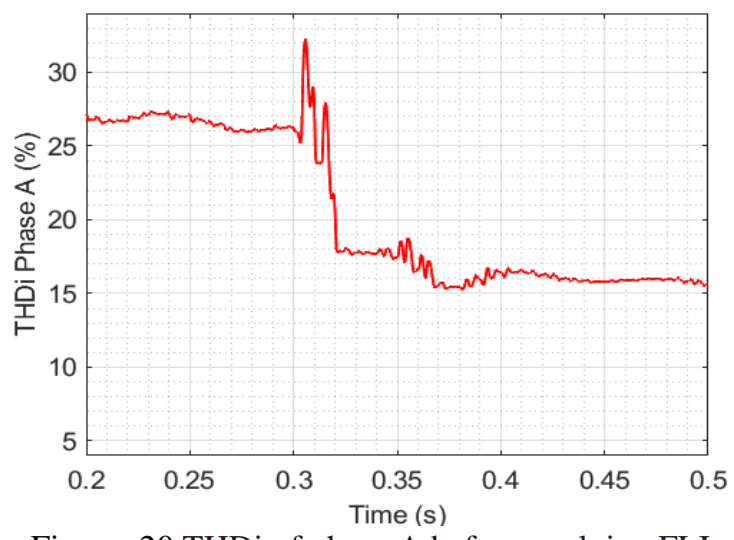

Figure. 20 THDi of phase A before applying FLI

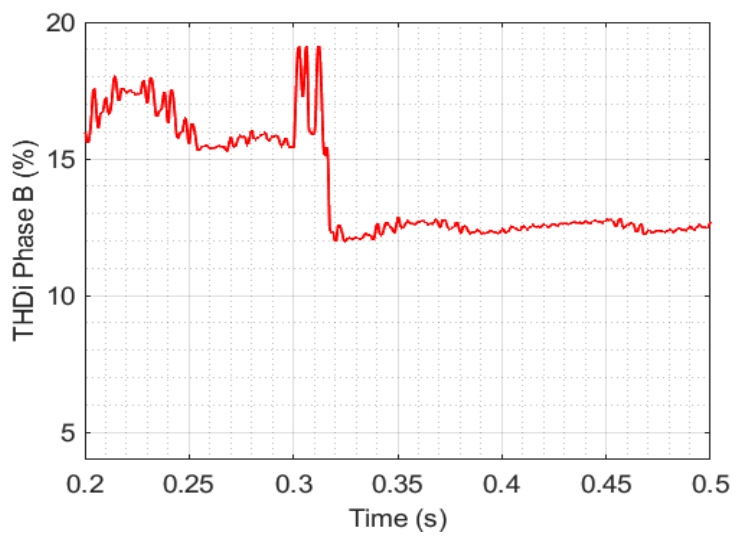

Figure. 21 THDi of phase B before applying FLI

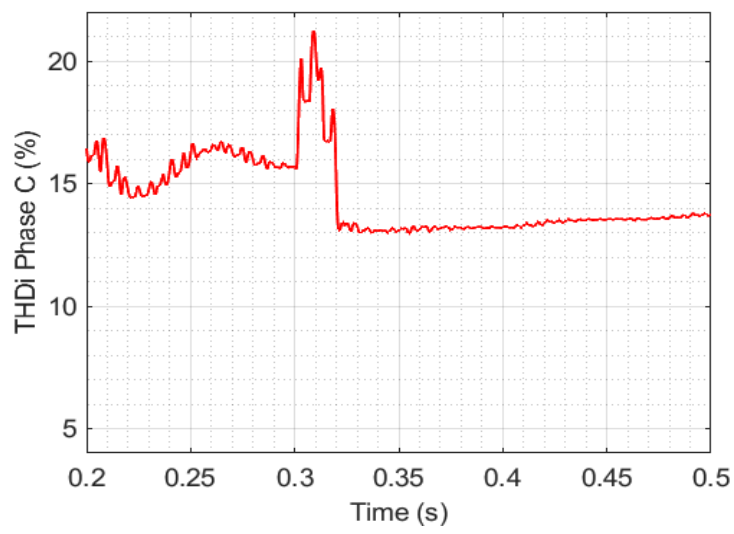

Figure. 22 THDi of phase C before applying FLI

unbalance and current harmonic. The OCNN controller obtains the lowest peak values under high transient conditions, such as $0.3 \mathrm{~s}-0.4 \mathrm{~s}$, namely

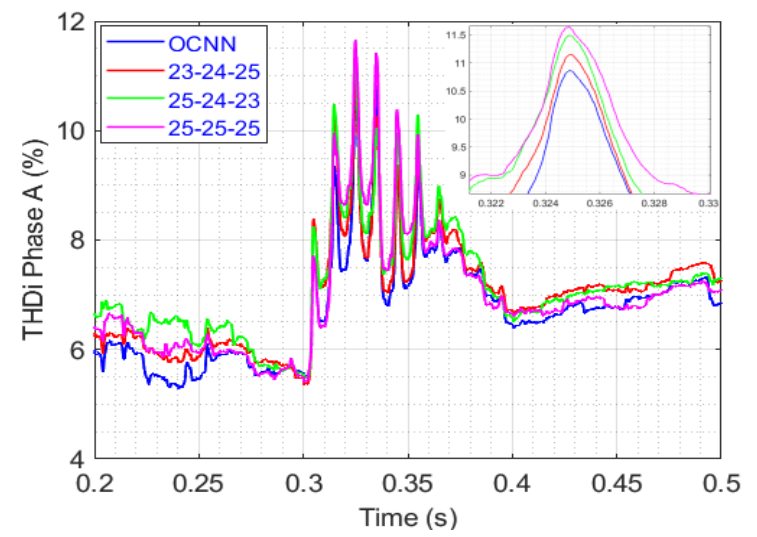

Figure. 23 THDi of phase A of the OCNN compared to LMNN

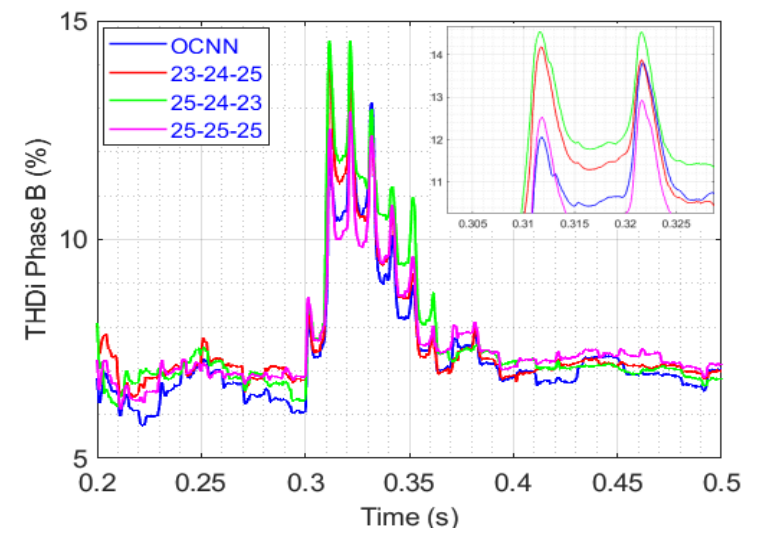

Figure. 24 THDi of phase B of the OCNN compared to LMNN

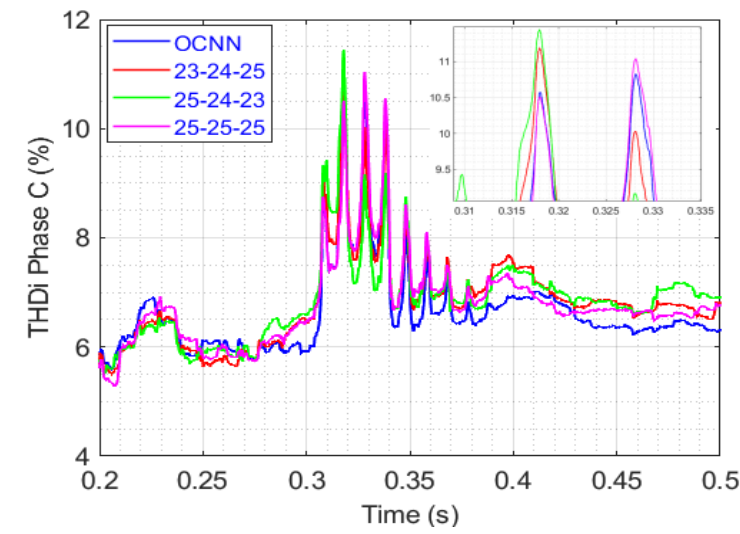


Figure. 25 THDi of phase $\mathrm{C}$ of the OCNN compared to LMNN

$2.62 \%$ for PCU and $6.73 \%, 7.33 \%$, and $6.63 \%$ for THDi, respectively, at phases $\mathrm{A}, \mathrm{B}$, and $\mathrm{C}$. In phases $\mathrm{A}, \mathrm{B}$, and $\mathrm{C}$, the system improved by $82.06 \%$ for PCU and 66.29 \%, $27.89 \%$, and 49.01\% for THDi, respectively, as compared to the system without FLI.

Table 6 compares the PCU and THDi values of the OCNN to the LMNN controllers. This table shows that the OCNN controller has the lowest values. However, even though each hidden layer has a bigger number of neurons, the results of LMNN simulations with varied configurations show a worse value.

\section{Conclusion}

This study revealed an innovative method to overcome current unbalance and harmonic issues, using OCNN on a single-phase PQ theory control system. FLI was equipped with a boost rectifier so they would have an unlimited DC source. This research has found that the OCNN control system worked well in a condition where loads and RS fluctuated. This study demonstrated that percent current unbalance (PCU) and current harmonics (THDi) in transient conditions have decreased. The proposed OCNN controller obtains the lowest peak value in the high transient condition. Compared to the system without FLI, the system improved by $82.06 \%$ for PCU and $66.29 \%, 27.89 \%, 49.01 \%$ for THDi, in phases $\mathrm{A}, \mathrm{B}$, and $\mathrm{C}$.

\section{Notations}

\begin{tabular}{|c|c|}
\hline$D C / A C$ & $\begin{array}{l}\text { circuitry that changes direct } \\
\text { current (DC) to alternating } \\
\text { current (AC) }\end{array}$ \\
\hline$a b c / \alpha \beta$ & $\begin{array}{l}\text { transformation of abc } \\
\text { coordinate to } \alpha \beta \text { coordinate }\end{array}$ \\
\hline$a b c / d q$ & $\begin{array}{l}\text { transformation of abc } \\
\text { coordinate to dq coordinate }\end{array}$ \\
\hline$i_{T L a}, i_{T L b}, i_{T L c}$ & current total load of each phase \\
\hline$v_{T L a}, v_{T L b}, v_{T L c}$ & $\begin{array}{l}\text { phase to the neutral voltage at } \\
\text { abc coordinate }\end{array}$ \\
\hline$v_{T L a, \alpha}, v_{T L b, \alpha}, v_{T L c, \alpha}$ & $\begin{array}{l}\text { phase to the neutral voltage at } \alpha \\
\text { coordinate }\end{array}$ \\
\hline$v_{T L a, \beta}, v_{T L b, \beta}, v_{T L c, \beta}$ & $\begin{array}{l}\text { phase to the neutral voltage at } \beta \\
\text { coordinate }\end{array}$ \\
\hline$v_{d c}, v_{d c}^{*}$ & $\begin{array}{l}\text { dc-link voltage and its voltage } \\
\text { reference }\end{array}$ \\
\hline $\begin{array}{l}P_{T L a}, P_{T L b}, P_{T L c} \\
P_{T L n}\end{array}$ & $\begin{array}{l}\text { fundamental active power at } \\
\text { abc coordinate }\end{array}$ \\
\hline${ }_{G b}, i *_{G c}, i *_{G n}$ & current reference \\
\hline
\end{tabular}

$\begin{array}{ll}P^{*} \text { phase } & \begin{array}{l}\text { active power reference of each } \\ \text { phase }\end{array} \\ P C U & \text { percent current unbalanced } \\ & \text { total harmonic distortion of } \\ & \text { current }\end{array}$

\section{Conflicts of interest}

The authors declare that they have no conflict of interest.

\section{Author contributions}

Dedy Kurnia Setiawan completed the conceptualization, formalization, analysis, validation, writing, editing, and revision of the manuscript under the direction and supervision of Mochamad Ashari and Heri Suryoatmojo.

\section{Acknowledgments}

This research was funded by Ministry of Research, Technology, and Higher Education Indonesia.

\section{References}

[1] M. Schmela, A. Beauvais, N. Chevillard, M. G. Paredes, M. Heisz, R. Rossi, M. Schmela, D. Whitten, J. Baca, and F. Telemcioglu. "Global Market Outlook: For Solar Power 2018-2022”, Solar Power Europe: Brussels, Belgium, 2018.

[2] C. Inês, P. L. Guilherme, M. G. Esther, G. Swantje, H. Stephen, and H. Lars, "Regulatory challenges and opportunities for collective renewable energy prosumers in the EU', Energy Policy, Vol. 138, p. 111212, 2020.

[3] S. Milčiuvienè, J. Kiršienè, E. Doheijo, R. Urbonas, and D. Milčius, "The Role of Renewable Energy Prosumers in Implementing Energy Justice Theory", Sustainability, Vol. 11, No. 19, 2019.

[4] A. Immonen, J. Kiljander, and M. Aro, "Consumer viewpoint on a new kind of energy market”, Electric Power Systems Research, Vol. 180, p. 106153, 2020.

[5] S. Parhizi, H. Lotfi, A. Khodaei, and S. Bahramirad, "State of the Art in Research on Microgrids: A Review", IEEE Access, Vol. 3, pp. 890-925, 2015.

[6] W. U. K. Tareen, M. Aamir, S. Mekhilef, M. Nakaoka, M. Seyedmahmoudian, B. Horan, M. A. Memon, and N. A. Baig, "Mitigation of Power Quality Issues Due to High Penetration of Renewable Energy Sources in Electric Grid Systems Using Three-Phase APF/STATCOM 
Technologies: A Review", Energies, Vol. 11, No. 6, 2018.

[7] S. Impram, S. V. Nese, and B. Oral, "Challenges of renewable energy penetration on power system flexibility: A survey", Energy Strategy Reviews, Vol. 31, p. 100539, 2020.

[8] M. J. H. Moghaddam, A. Kalam, M. R. Miveh, A. Naderipour, F. H. Gandoman, A. A. Ghadimi, and Z. A. Malek, "Improved Voltage Unbalance and Harmonics Compensation Control Strategy for an Isolated Microgrid", Energies, Vol. 11, No. 10, 2018.

[9] A. D. Martin, R. S. Herrera, J. R. Vazquez, P. Crolla, and G. M. Burt, "Unbalance and harmonic distortion assessment in an experimental distribution network", Electric Power Systems Research, Vol. 127, pp. 271-279, 2015.

[10] M. Rane and S. Wagh, "Mitigation of harmonics and unbalanced source voltage condition in standalone microgrid: positive sequence component and dynamic phasor based compensator with real-time approach", Heliyon, Vol. 5, No. 2, p. e01178, 2019.

[11] A. Trivedi and J. Saroha, "Voltage unbalance and harmonics compensation in AC microgrid using add-on repetitive controller", International Transactions on Electrical Energy Systems, Vol. 30, No. 4, p. e12290, 2020.

[12] T. Tran, D. Raisz, and A. Monti, "Harmonic and unbalanced voltage compensation with VOCbased three-phase four-leg inverters in islanded microgrids", IET Power Electronics, Vol. 13, No. 11, pp. 2281-2292, 2020.

[13] V. Khadkikar and A. Chandra, "A Novel Structure for Three-Phase Four-Wire Distribution System Utilizing Unified Power Quality Conditioner (UPQC)", IEEE Transactions on Industry Applications, Vol. 45, No. 5, pp. 1897-1902, 2009.

[14] D. K. Setiawan, H. Suryoatmojo, and M. Ashari, "Four-leg Voltage Source Inverter for Voltage and Current Balancing of Distribution Transformer with Distributed Generations", In: Proc. of International Seminar on Intelligent Technology and Its Applications, Surabaya, Indonesia, pp. 93-98, 2018.

[15] D. K. Setiawan, M. Ashari, and H. Suryoatmojo, "FLI for Unbalanced and Harmonic Current Mitigation in Rooftop Solar Connected Distribution Network", In: Proc. of International Seminar on Intelligent Technology and Its Applications, Surabaya, Indonesia, pp. 173-178, 2021.
[16] H. Arghavani and M. Peyravi, "Unbalanced current-based tariff", CIRED-Open Access Proceedings Journal, Vol. 2017, No. 1, pp. 883887, 2017.

[17] I. Vechiu, O. Curea, and H. Camblong, "Transient Operation of a Four-Leg Inverter for Autonomous Applications With Unbalanced Load", IEEE Transactions on Power Electronics, Vol. 25, No. 2, pp. 399-407, 2010.

[18] I. Vechiu, H. Camblong, G. Tapia, B. Dakyo, and O. Curea, "Control of four leg inverter for hybrid power system applications with unbalanced load", Energy Conversion and Management, Vol. 48, No. 7, pp. 2119-2128, 2007.

[19] I. Vechiu, O. Curea, H. Camblong, S. Ceballos, and J. L. Villate, "Digital control of a threephase four-leg inverter under unbalanced voltage conditions", In: Proc. of European Conference on Power Electronics and Applications, Aalborg, Denmark, pp. 1-10, 2007.

[20] M. B. Delghavi and A. Yazdani, "IslandedMode Control of Electronically Coupled Distributed-Resource Units Under Unbalanced and Nonlinear Load Conditions", IEEE Transactions on Power Delivery, Vol. 26, No. 2, pp. 661-673, 2011.

[21] M. Hamzeh, S. Emamian, H. Karimi, and J. Mahseredjian, "Robust Control of an Islanded Microgrid Under Unbalanced and Nonlinear Load Conditions", IEEE Journal of Emerging and Selected Topics in Power Electronics, Vol. 4, No. 2, pp. 512-520, 2016.

[22] M. H. D. F. Takami, S. A. O. D. Silva, and L. P. Sampaio, "Dynamic performance comparison involving grid-connected PV systems operating with active power-line conditioning and subjected to sudden solar irradiation changes", IET Renewable Power Generation, Vol. 13, No. 4, pp. 587-597, 2019.

[23] O. I. Abiodun, A. Jantan, A. E. Omolara, K. V. Dada, N. A. Mohamed, and H. Arshad, "Stateof-the-art in artificial neural network applications: A survey", Heliyon, Vol. 4, No. 11, p. e00938, 2018.

[24] Y. Fang, J. Fei, and K. Ma, "Model reference adaptive sliding mode control using RBF neural network for active power filter", International Journal of Electrical Power \& Energy Systems, Vol. 73, pp. 249-258, 2015.

[25] Z. Sabir, M. R. Ali, M. A. Z. Raja, M. Shoaib, R. A. S. Núñez, and R. Sadat, "Computational intelligence approach using LevenbergMarquardt backpropagation neural networks to solve the fourth-order nonlinear system of 
Emden-Fowler model", Engineering with Computers, 2021.

[26] M. Umar, Z. Sabir, M. A. Z. Raja, M. Gupta, D. N. Le, A. A. Aly, and Y. G. Sánchez, "Computational Intelligent Paradigms to Solve the Nonlinear SIR System for Spreading Infection and Treatment Using LevenbergMarquardt Backpropagation", Symmetry, Vol. 13, No. 4, 2021.

[27] J. L. Aljohani, E. S. Alaidarous, M. A. Zahoor Raja, M. S. Alhothuali, and M. Shoaib, "Backpropagation of Levenberg Marquardt artificial neural networks for wire coating analysis in the bath of Sisko fluid", Ain Shams Engineering Journal, 2021.

[28] K. H. Tan, F. J. Lin, J. H. Chen, K. H. Tan, F. J. Lin, and J. H. Chen, "A Three-Phase Four-Leg Inverter-Based Active Power Filter for Unbalanced Current Compensation Using a Petri Probabilistic Fuzzy Neural Network", Energies, Vol. 10, No. 12, p. 2005, 2017.

[29] J. Jayachandran and R. M. Sachithanandam, "ANN based controller for three phase four leg shunt active filter for power quality improvement", Ain Shams Engineering Journal, Vol. 7, No. 1, pp. 275-292, 2016.

[30] K. F. Weaver, V. Morales, S. L. Dunn, K. Godde, and P. F. Weaver. "Pearson's and Spearman's Correlation", An Introduction to Statistical Analysis in Research, John Wiley \& Sons, Ltd, pp. 435-471, 2017.

[31] D. K. Setiawan, M. Ashari, and H. Suryoatmojo, "Harmonics Reduction for Four-Leg Distribution Network-Connected Single Phase Transformerless PV Inverter System Using Diagonal Recurrent Neural Network", In: Proc. of International Conference of Artificial Intelligence and Information Technology, Yogjakarta, Indonesia, pp. 331-335, 2019.

[32] D. K. Setiawan, M. Ashari, H. Suryoatmojo, and W. Cahyadi, "Combined Error Adaptive FuzzyPI for Reducing DC Voltage Ripple in Three Phase SPWM Boost Rectifier Under Unbalanced DGs System", International Journal of Intelligent Engineering and Systems, Vol. 13, No. 3, pp. 384-395, 2020.

[33] V. Khadkikar and A. Chandra, "Three-Phase and Single-Phase p-q Theories Applied to ThreePhase Shunt Active Power Filter under Different Operating Conditions: A Comparative Evaluation", International Journal of Emerging Electric Power Systems, Vol. 11, 2010. 